\title{
The Estimated Aspect of Speech Associative Representation of Mental States
}

\author{
${ }^{\text {*1}}$ Ekaterina M. Alekseeva, ${ }^{2}$ Aliya A. Singatullova \\ ${ }^{1,2}$ Kazan Federal University, Institute of International Relations, History and Oriental Studies \\ *Email: ealekseeva@ @ist.ru, Contact +79063219552
}

\section{Received: 15th December 2017, Accepted: 20th December 2017, Published: 31st December 2017}

\begin{abstract}
The article deals with associative speech representation of mental states, its evaluation aspect. 32 students of the Kazan Federal University (26 females and 6 males) aged from 18 to 22 years took part in an association experiment, developed on the basis of the DMDX program. The time of speech reaction to the presented stimuli - the concepts of 25 mental states was determined. The subjects had to estimate the states by answering the question "what?" and giving an adjective. The average time of the estimated response to the concepts of states on the computer monitor was 2246,9 milliseconds. Associative speech estimated reaction turned out to be the fastest to the stimuli "expectation" $(1182,9$ milliseconds), "thought" (1603,8 milliseconds), "fatigue" (1654,8 milliseconds), the slowest - to the stimuli "remorse" (2808,5 milliseconds) and "nervousness" (2743,3 milliseconds). 463 associative speech reactions in the form of adjectives were given by the subjects to the concepts of 25 states, on average by 18,5 adjectives for each state. The concepts amorousness and remorse have the largest number of speech estimated associations (by 23 different adjectives). The least number of evaluative associations are characterized by the concepts thoughts, delight and indecision (by 15 adjectives). The most pronounced nucleus is the evaluative associative fields of states thoughts and delight. The evaluative associative fields of mental states are distinguished by the presence of nearnuclear layers and sufficiently densely filled periphery.
\end{abstract}

Keywords: Mental State, Evaluative Associative Representation, Association Experiment, Speech Response.

\section{Introduction}

The study of the associative representation of mental phenomena (and, first and foremost, emotions and mental states) is of great scientific interest. The question of the structure of the organization of knowledge about emotions, the development of this knowledge in the course of ontogenesis [1], the representation of emotions at different consciousness levels [2], the level organization of mental representations of mental states, their linguistic features [3-6] and others has already been raised. In view of the fact that states as a mental phenomenon are an individual and subjective phenomenon of the psyche, it is necessary to investigate the universal and specific components of associative representations of mental states. This will demonstrate the important patterns in the formation of the structure of associative representations of the world on the whole and about oneself.

The purpose of this paper was to study the estimated associative speech representation of mental states. The research tasks lied in reconstructing the evaluative associative fields of mental states and in determining the time of associative speech response to visually presented names of mental states.

The very associative method is by no means novel. The associative experiment was the most widespread when its participants needed to give their associations in writing to certain concepts [7]. Oral associations, as well as the oral associations during the psycholinguistic experiment being conducted in the conditions of time constraint, are studied considerably less.

An experimental procedure allowing to measure the time of a speech response to the concepts of mental states presented on the monitor with an accuracy of milliseconds was used in the present research.

\section{Methods}

An association experiment based on the DMDX program [7] was carried out. The instruction for the test subjects was presented in the printed form on a sheet of paper and was as follows:

"Good afternoon, dear research participant!

Our research has an associative nature. You will be shown the names of mental states on the screen of the monitor. Your task is to estimate the mental state presented by answering the question "what?" and to name the first association that comes to your mind in the form of an adjective as soon as possible.

Before presenting the name of this or that mental state, a cross appears on the screen for fixation of your attention. This is an indication that you are to concentrate. Answer as quickly as possible, without long hesitation".

Stimuli are the names of states of pity, pleasure, jealousy, liking, expectation, love, fatigue, remorse, thoughts, fatigue, delight, tranquility, melancholy, joy, uncertainty, amorousness, indecision, happiness, compassion, excitement, vigour, inspiration, loneliness, interest, cheerfulness. 
Later, the respondents' answers were analyzed with regard to speech reaction time by using the program Check Vocal [8].

\section{Results}

The average speech estimated reaction time to the stimuli - the names of mental states, presented on the computer monitor, was 2246,9 milliseconds. Figure 1 shows the reaction time for each singular stimulus.

Fig. 1. The Average Reaction Time to the Stimuli - Names of Mental States (in Milliseconds)

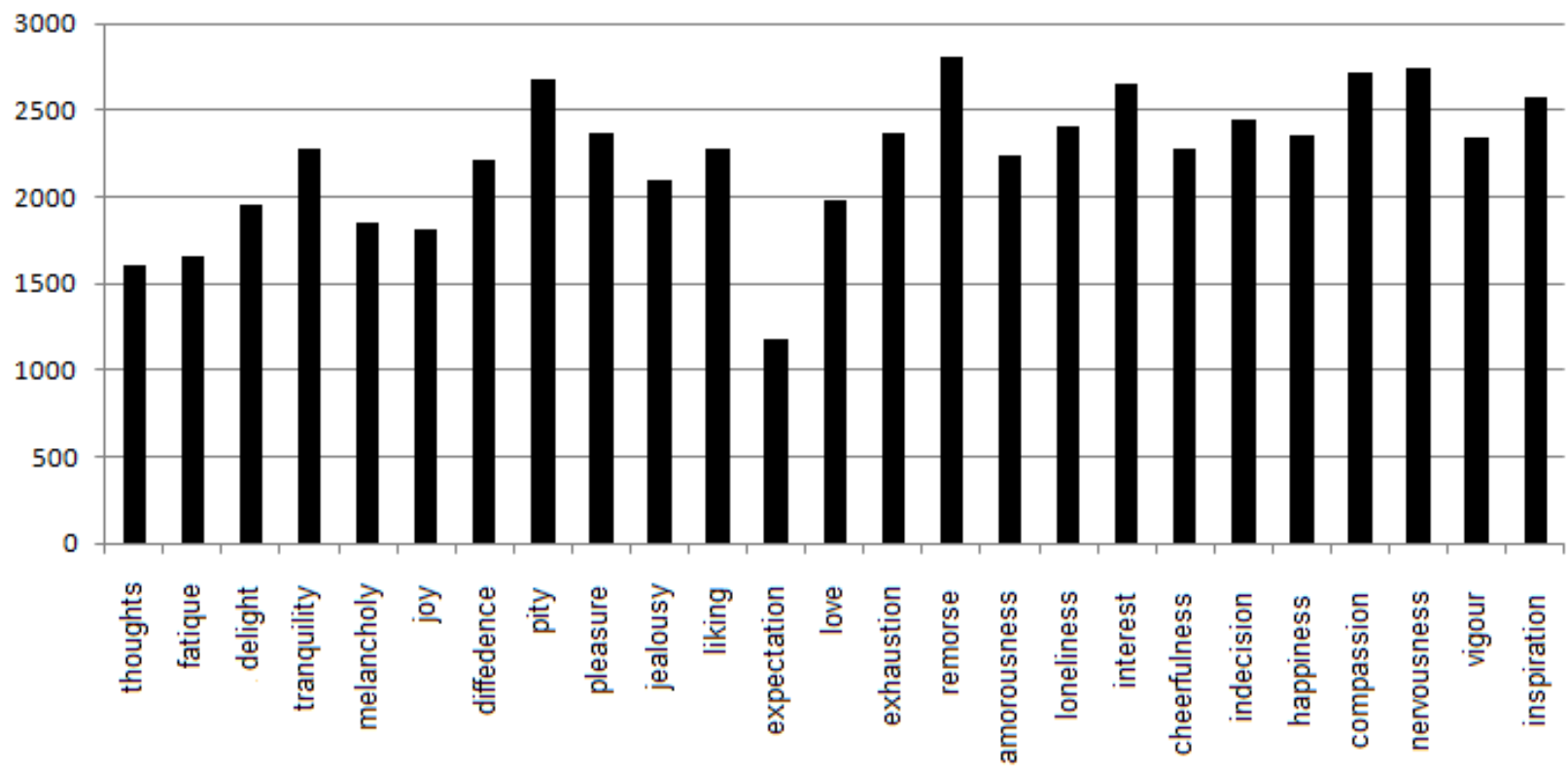

It follows from Figure 1 that the fastest associative speech response to the concepts of the states "expectation" (1182,9 milliseconds.), "thoughts" (1603,8 milliseconds), "fatigue" (1654,8 milliseconds), "melancholy" (1852,1 milliseconds), "joy" (1817,4 milliseconds), "delight" (1960,3 milliseconds), "love" (1975,7 milliseconds). The speech reaction rate to the rest stimuli was more than 2 seconds. The reaction of speech to the stimuli "remorse" (2808,5 milliseconds), "nervousness" (2743 milliseconds), “compassion" (2713,9 milliseconds), "pity" (2675,3 milliseconds) proved to be the slowest.
Afterwards the speech reactions were analyzed qualitatively in order to reconstruct the estimated associative fields. It was determined how many speech reactions- adjectives to the names of mental states formed the periphery, the near-nuclear layers and the core of the estimated associative fields. The most typical associations adjectives, inherent in at least $30 \%$ of the respondents, entered into the core of the estimated associative state fields. The adjectives, representing the answers that occurred more than once, formed the near-nuclear layers. The individual speech reactions of the subjects turned out on the periphery.

Table 1. The Number of Associative Reactions-Adjectives to the Stimuli - Names of Mental States

\begin{tabular}{|l|c|c|c|c|}
\hline \multicolumn{1}{|c|}{ Mental state } & $\begin{array}{c}\text { The general } \\
\text { number of } \\
\text { adjectives- } \\
\text { associations }\end{array}$ & $\begin{array}{c}\text { The nucleus of } \\
\text { associative field }\end{array}$ & $\begin{array}{c}\text { The near-nuclear } \\
\text { layers of } \\
\text { associative field }\end{array}$ & $\begin{array}{c}\text { The periphery of } \\
\text { associative field }\end{array}$ \\
\hline thoughts & 15 & 1 & 4 & 10 \\
\hline fatigue & 19 & 1 & 1 & 14 \\
\hline delight & 15 & & 2 & 15 \\
\hline tranquility & 17 & 4 & 14 \\
\hline melancholy & 18 & & 4 & 15 \\
\hline joy & 19 & & & 13 \\
\hline
\end{tabular}




\begin{tabular}{|c|c|c|c|}
\hline uncertainty & 18 & 2 & 16 \\
\hline pity & 17 & 3 & 14 \\
\hline pleasure & 21 & 3 & 18 \\
\hline jealousness & 22 & 4 & 18 \\
\hline liking & 19 & 6 & 13 \\
\hline expectation & 17 & 3 & 14 \\
\hline love & 20 & 8 & 12 \\
\hline exhaustion & 18 & 4 & 14 \\
\hline remorse & 23 & 2 & 21 \\
\hline amorousness & 23 & 2 & 21 \\
\hline loneliness & 16 & 5 & 11 \\
\hline interest & 19 & 4 & 15 \\
\hline cheerfulness & 18 & 4 & 14 \\
\hline indecision & 14 & 5 & 9 \\
\hline happiness & 21 & 5 & 16 \\
\hline compassion & 16 & 3 & 13 \\
\hline nervousness & 21 & 4 & 17 \\
\hline vigour & 17 & 5 & 12 \\
\hline inspiration & 19 & 3 & 16 \\
\hline TOTAL & \multicolumn{3}{|c|}{463 adjectives } \\
\hline
\end{tabular}

As shown by the data in Table 1, 463 associations the speech reactions (adjectives) were given by the subjects to the concepts of 25 mental states, that is, to each of the 25 concepts of the states on average by 18,5 associative adjectives. Most of speech estimated associations were given to the concepts remorse and amorousness (by 23 various adjectives), jealousness (22 adjectives), pleasure, nervousness, happiness (by 21 adjectives). The minute quantity of associations was given to indecision (14 adjectives), thoughts and delight (by 15 adjectives), loneliness (16 adjectives), tranquility, pity, expectation and vigour (by 17 adjectives).

The majority of the states under consideration do not have a clear nucleus of associative field. The pronounced nucleus is only in the estimated associative fields of the states thoughts and delight (by one "nuclear" adjective). The near-nuclear layers of the estimated associative field of the states love ( 8 adjectives), liking ( 6 adjectives) are most fully filled. The near-nuclear layers of the estimated associative field of the states delight (1 adjective), tranquility, uncertainty, remorse (by 2 adjectives), pity, pleasure, expectation, compassion, inspiration (by 3 adjectives) are least filled of all.
The estimated associative fields of mental states are characterized by fairly densely filled peripheral layers. The associative fields of the states of remorse (21 adjectives), amorousness (19 adjectives), pleasure and jealousy (by 18 adjectives), nervousness (17 adjectives) have the richest periphery. The states of indecision (9 adjectives), thoughts (10 adjectives), loneliness (11 adjectives), vigour (12 adjectives) are distinguished by the least represented periphery.

Let us analyze the most significant estimated associative fields of states.

Thus, the estimated speech reactions to the concept of the state of interest, characterized by a cognitive and motivational constituent part, revealed the following features: the near-nuclear layer comprehended the adjectives interesting ( $18 \%$ of the subjects), great, deep (by 11\%), intelligent (7\%). The periphery of the estimated associative field constituted the adjectives frequent, open, exciting, confident, inquisitive, joyful, fast, inspired, pleasant, partial, lively, great, attentive, mutual.

The estimated associative field of the cognitive mental state "thought" consists of the nucleus long (30\% of the respondents), the near-nuclear layer is 
filled with the adjectives large, deep, thoughtful, intelligent (by 7\%). The periphery is represented by the estimated associations such as strange, fast, painful, onerous, heavy, full, exciting, unique, complex.

When analyzing the estimated speech responses to the concepts of mental states with the dominant physiological component, it was found that the nearnuclear layers (the nucleus is absent) of the estimated associative field "fatigue" comprehended the adjectives strong (13\% of the respondents), languid (13\%), weak (10\%), boring (6\%), tired $(6 \%)$. The adjectives long, heavy, onerous, working, languishing, lonely, bad, not good, black, tired, pleasant are on the periphery.

The very adjective "fatigued / tired" as an estimated speech response entered into the near-nuclear layers of the estimated associative field "fatigue" (16\%), which also encompassed the adjectives deep, strong, heavy (by 8\%). The words everyday, sleepy, high, melancholy, easy, bad, uncontrollable, bad, incomprehensible, long-expected, uncomfortable, weak, evening, boring entered into the periphery.

The estimated associative field of the state "vigour" has the near-nuclear layers, which included the adjectives morning ( $21 \%$ of the respondents), bright, active, cheerful (8\%). The adjectives cheerful, spiritual, hearty, healthy, frisky, inspiring, strong, fresh, excellent, frosty, confident have formed the periphery.

Of interest are estimated associative fields of emotional mental states. So, the associative field of the state "delight" consists of a rather pronounced nucleus - the adjective joyful (33\% of the subjects) and the near-nuclear layer, filled with the adjective strong (18\% of the subjects). The periphery is represented by the adjectives long, cheerful, fairylike, huge, multi-coloured, expressive, strange, emotional, kind, delighted, supreme, colourful, wild.

The estimated associative fields of the states "joy", "happiness" and "cheerfulness" do not have an unambiguously expressed nucleus and on the whole show similar characteristics with the associative field of the state of "delight". The near-nuclear layers of the state "joy" include the adjectives cheerful and happy (14\% of the subjects), large $(10 \%)$, huge $(7 \%)$, the near-nuclear layers of the state "cheerfulness" are filled with words joyous (28\%), bright, cheerful and happy (by $7 \%$ ), meeting with friends $(10 \%)$, holiday $(6 \%)$, and the nearnuclear layers of the state "happiness" are characterized by the adjectives large (13\% of the subjects), joyful and cheerful (by 10\%) and huge and beautiful $(6 \%)$.

The state of pleasure is characterized by the nearnuclear layers, filled with the adjectives pleasant and good $(14 \%)$, satisfied $(7 \%)$, and the periphery with the adjectives strange, prolonged, huge, strong, admired, viscous, tasty, indescribable, saturated, majestic, short, happy, calm, beautiful, joyous, pink, merry.

The near-nuclear layers of the estimated associative field of the state "liking" are filled with the words in love with and beautiful (13\% of the respondents), pleasant (10\%), mutual, strong, good (by 6\%). Liking is also magnificent, impressive, big, exciting, dangerous, normal, bright, joyous, delighted, cheerful, small, sincere, open-minded.

The near-nuclear layers of the estimated associative field of the state "inspiration" with the emotional and motivational components include the adjectives large (16\%), exciting and easy (by $8 \%$ ). The following estimations of the state of inspiration are on the periphery: comprehensive, gentle, cheerful, unexpected, inspiring, soaring, vigorous, excellent, conscious, impetuous, interested, happy, confident, open, inspired.

Let's consider the estimated associative characteristics of the states of love and amorousness. As follows from Table 1, in total 20 estimated associations-adjectives ( 8 of them form near-nuclear layers) were allotted to the concept of the mental state of love, and 23 ( 2 of which enter into the nearnuclear layers) - to the concept of amorousness. The near-nuclear layers of the estimated associative field of the state of love included the adjectives everlasting and great (19\% of the respondents), mutual, strong, enamoured, ecstatic, passionate, red (by 6\%), and the state of amorousness - happy (11), beautiful $(7 \%)$. The adjectives great, warming, tender, light, wholehearted, strange, beautiful, glad, dimensionless, fine, unselfish, happy filled the periphery of the estimated associative field of the state of love, and the state of amorousness is filled with the adjectives strange, inspired, early, sincere, pleasant, troublesome, first, spring, light, transient, beloved, pink, playful, fast, uncertain, superficial, airy, delighted, beautiful, fluttering, momentary. Thus, the states of love and amorousness are characterized by different features of the estimated associative fields: while the estimated associative field of the state of love consists of fairly distinct near-nuclear layers, the periphery is richly represented in the state of amorousness.

The negative states of low level of mental activity are distinguished by their own features. Thus, the near-nuclear layers of the associative field of the state "melancholy" are formed by the adjectives melancholy (23\%), sad (13\%), large (10\%), boring and black (by 6\%). The adjectives long, dull, lonely, depressed, deaf, black, heavy, strange, bad, deep, gray, fatigued are on the periphery.

The state of uncertainty is characterized by the presence of the near-nuclear layer of the estimated 
associative field, which includes the adjectives uneasy and weak (10\% of the subjects). The periphery was filled with the adjectives terrible, constraining, constant, strong, timid, incomprehensible, wild, strange, inexact, fragile, uncertain, insecure, big, disturbing, eternal.

The similar characteristics show the state of indecision. It is uncertain (15\%), strong, reasonable, weak, shy (by 10\%). In addition, it is tedious, strange, rare, troubled, unsuccessful, vague, huge, frequent (the periphery of the estimated associative field).

The near-nuclear layers of the estimated associative field of the state of loneliness was formed by the adjectives sad and melancholy (by $15 \%$ of the respondents), terrible (11\%), long and lonely (7\%). The adjectives unpleasant, terrifying, complete, calm, uncertain, short, bad, boring, compassionate, gray, chronic are on the periphery.

\section{Discussion}

It was more difficult for the participants of the experiment to estimate the states on the computer monitor in the form of adjectives (the average time was 2246,9 milliseconds, rather than to give free associations to these states (the average time 2114,68 milliseconds).

One can single out the states characterized by a fast and slow rate of speech evaluation.

Reconstruction of the estimated associative fields has shown that only the state of delight has a nucleus represented by a speech estimated reaction, which was given by more than $33 \%$ of the subjects. The nucleus of the state of thoughts was estimated by $30 \%$ of the participants of the experiment.

All analyzed states are characterized by the presence of multi-layered near-nuclear formations (from 1 to 8 layers) of the estimated associative field.

On the periphery of the estimated associative field there are the adjectives that are from 9 to 21 in number.

\section{Summary}

The average time of the speech estimated associative reaction to the names of mental states was 2246,9 milliseconds. These meanings are significantly higher than the reaction time found in the psycholinguistic experiments, where it was necessary to name the stimuli presented on the computer monitor in the form of the whole sentences, coherent phrases or individual words [9].

463 estimated associations (adjectives) were given to the concepts of mental states, on the average by 18,5 adjectives per state. The estimated speech responses to the names of mental states can form a nucleus (the most typical associations are adjectives), the near-nuclear layers and the periphery of estimated associative fields.

The conducted study showed that only the estimated associative fields of mental states of thoughts and delight have the clearly expressed nucleus, while the near-nuclear layers and the densely filled periphery are characteristic of the majority of evaluative associative fields.

\section{Conclusion}

On the basis of the obtained data, it became possible to study the quantitative and qualitative features of speech estimated associative reactions to the names of mental states, and also to reconstruct the estimated associative fields of the studied mental states. This contributes to the development of a structure-level model of representations of mental states, in which the level of assessment is of key importance.

The prospects for the research consist in conducting a study of situational associative representation of mental states, where, as a verbal association, the subjects should name a situation of which a particular state is characteristic.

\section{Acknowledgements}

The work is performed according to the Russian Government Program of Competitive Growth of Kazan Federal University.

\section{References}

[1] O.A. Prusakova, E.A. Sergienko, Representations of the Emotions by the Children Aged From 3 to 6 Years, Scientific Search, Issue 3, Yaroslavl, p. 51-64, 2002.

[2] L.Y. Dorfman, Emotions in Art: Theoretical Approaches and Empirical Research, Moscow, 424 p., 1997.

[3] A.V. Chernov, E.M. Alekseeva, Estimated characteristics of mental states' representations, Journal of organizational culture, communications and conflict, Vol. 20, Sp. Is. 2, pp. 94-99, 2016.

[4] E.M. Alekseeva, A.M. Bulatova, Associative representation of mental state concepts in the bilingual mental lexicon, Turkish online journal of design art and communication, Vol. 6, Is., pp. 23092316, 2016.

[5] A.M. Bulatova, E.M. Alekseeva, Lexical objectivation means for the emotional concept fear in German publicistic discourse, Turkish online journal of design art and communication, Vol. 6, Is., pp. 2334-2339, 2016.

[6] E.M. Alexeyeva, A.V. Chernov, Representation of mental states: Associative level, Social Sciences (Pakistan), Vol. 10, Is. 7, pp.1959-1963, 2015.

[7] L.A. Pautova, Association Experiment: The Experience of Sociological Application, Sociology: 
Methodology, Methods, Mathematical Models, № 24, p. 149-168, 2007.

[8] K.I. Forster, J.C. Forster, DMDX: A Windows display program with millisecond accuracy, Behavior Research Methods, Instruments, and Computers, 35 (1), pp. 116-124, 2003.

[9] A. Protopapas, CheckVocal: A program to facilitate checking the accuracy and response time of vocal responses from DMDX, Behaviour Research Methods, 39, pp. 859-862, 2007.

[10] A. Mädebach, E. Alekseeva, J.D. Jescheniak, Word order does not constrain phonological activation in single word production, Journal of Cognitive Psychology, 23 (7), pp. 837-842, 2011. 